\title{
Warm-Mix Asphalt and Pavement Sustainability: A Review
}

\author{
Kenneth A. Tutu1, Yaw A. Tuffour ${ }^{2}$ \\ ${ }^{1}$ Department of Civil Engineering, Auburn University, Auburn, AL, USA \\ ${ }^{2}$ Department of Civil Engineering, Kwame Nkrumah University of Science and Technology, Kumasi, Ghana \\ Email: yat@engineer.com
}

Received 10 December 2015; accepted 6 March 2016; published 9 March 2016

Copyright (C) 2016 by authors and Scientific Research Publishing Inc.

This work is licensed under the Creative Commons Attribution International License (CC BY).

http://creativecommons.org/licenses/by/4.0/

(c) (i) Open Access

\begin{abstract}
Within the past two decades or so, the asphalt paving industry has responded positively to increasing global concerns over shrinking natural resource reserves and worsening environmental conditions through the development and deployment of warm-mix asphalt technologies. Such technologies make it possible to produce and place asphalt concrete at reduced temperatures compared to conventional hot-mix methods. Several studies have reported on the potential of warm-mix asphalt with regard to improved pavement performance, efficiency and environmental stewardship. This paper reviews several of those studies in the context of pavement sustainability. Overall, warm-mix asphalt provides substantial sustainability benefits similar to or, in some cases, better than conventional hot-mix asphalt. Sustainability benefits include lower energy use, reduced emissions, and potential for increased reclaimed asphalt pavement usage. Growth in utilization of warm-mix asphalt worldwide may, in the not-too-distant future, make the material the standard for asphalt paving. Regardless, there are concerns over some aspects of warm-mix asphalt such as lower resistance to fatigue cracking, rutting and potential water-susceptibility problems, particularly with mixes prepared with water-based technologies, which require further research to address.
\end{abstract}

\section{Keywords}

Warm-Mix Asphalt, Pavement Sustainability, Lower Energy Use, Reduced Emissions

\section{Introduction}

Global concerns over the gradual depletion of non-renewable natural resources and increasing damage to the environment from greenhouse gas emissions have created greater awareness, within the past two decades, for sustainable development practices in all spheres of human endeavor including the road construction industry. 
Within the construction industry, pavement construction and maintenance are known to be resource-intensive, sometimes with considerable negative environmental impacts. It is reported that in the United States (US) alone, over 320 million tons of raw materials are used in the construction, rehabilitation, and maintenance of the country’s road network annually at a cost of over $\$ 150$ billion [1] [2]. On a global scale, the amount of raw material and energy usage in the construction industry and the associated cost could be staggering. This emphasizes the need, and places responsibility on professionals within the industry, to indulge in sustainable construction practices, in order to ensure that the activities of today's generation would not compromise the ability of tomorrow's generation to meet its needs [3].

Within the past two decades or so, the asphalt paving industry has responded positively to the need for sustainable practices within the industry through the development and deployment of warm-mix asphalt (WMA) technologies. Warm-mix asphalt is an innovative asphalt concrete produced at temperatures about $20^{\circ} \mathrm{C}-40^{\circ} \mathrm{C}$ lower than those employed in the production of conventional hot-mix asphalt and yet still have at least the same properties as conventional hot-mix. Currently, WMA technologies lie at the core of the paving industry's efforts to gear practices and operations toward sustainable development. Such practices require minimization of energy consumption, use of non-renewable resources, and reduction in the amounts of pollutants generated during the production of paving materials in the most cost-effective manner [4] [5]. Sustainable pavement development must reduce the use of virgin materials, ensure safe, comfortable, and cost-effective travel and minimize waste generation [6]. Uzarowski and Moore [7] have emphasized environmental friendliness as a key requirement to be met by sustainable pavements.

Asphalt concrete is a versatile and common pavement construction material traditionally produced at temperatures between $150^{\circ} \mathrm{C}$ and $170^{\circ} \mathrm{C}$. Even though emissions from asphalt plant operations are touted to be low compared to those from other industrial operations [8], increasing sustainable development concerns require that the asphalt industry further improve the sustainability of its practices by utilizing innovative construction materials to ensure efficiency, environmental conservation, and enhanced social benefits. Warm-mix asphalt production is set in the long-term to do exactly that. Originally explored for its environmental benefits, WMA has now been discovered to have numerous construction and performance benefits [8].

The motivation for WMA development was derived from the Kyoto Protocol which emphasized a worldwide concerted effort to reduce greenhouse gas emissions into the atmosphere. More recently, though, additional impetus has come from the United Nations Climate Summit held on September 23, 2014 in New York, at which world leaders and several organizations announced strong commitments to cut greenhouse gas emissions [9]. Within a broader context, the concept of pavement sustainability covers the planning, design, construction, operation and disposal phases of pavement development; however, this paper focuses on the role of pavement materials in pavement sustainability. In particular, it presents a review of literature on the environmental friendliness, performance, economic and social benefits, as well as limitations of and concerns with warm mix asphalt in the asphalt paving industry.

\section{Warm-Mix ${ }^{1}$ Asphalt Technologies}

\subsection{Background}

Asphalt concrete consists of mineral aggregate and asphalt cement blended at high temperatures, hence, the term hot-mix asphalt (HMA). The high temperatures are employed in order to be able to dry the aggregates, which constitute about $95 \%$ by weight of the mix, and reduce the viscosity of the binder to enable proper and uniform aggregate coating and mix workability. Mixes containing polymer-modified binders may require even higher temperatures to obtain satisfactory viscosity and meet the need for wider compaction window [10]. By far, aggregate heating is the most expensive operation and a major bottleneck in asphalt plant operations [11]. Production of the mix at high temperatures is a source of concern as it requires high energy use, results in binder aging in the hot-mix plant and the generation of greenhouse gases. To address these concerns, the asphalt industry has developed warm-mix asphalt technologies that enable the production of asphalt mixes at temperatures that are $20^{\circ} \mathrm{C}-40^{\circ} \mathrm{C}$ lower than conventional HMA production temperatures. The lower production temperatures are as a result of reduction in binder viscosity achieved through rheological modification while providing for complete coating of aggregates and workability of the mix at lower temperatures with the expectation that the mix possesses strength, durability, and performance characteristics similar to or better than HMA [12] [13].

${ }^{1}$ Warm-mix asphalts. 
WMA technologies were pioneered in Europe [14] following the European Union's pledge to reduce carbon dioxide (a potent greenhouse gas) emissions by 15\% by 2010 under the Kyoto Protocol. The asphalt industry in Europe began to explore technologies to construct asphalt pavements at reduced temperatures [15] [16]. The first pavement trials involving WMA were constructed in Germany and Norway between 1995 and 1999, followed by the first highway project in Germany in 1999 with Aspha-min zeolite-treated mix [17]. Following the United States' National Asphalt Pavement Association (NAPA) WMA study tour of Europe in 2002, there has been a growing interest in WMA in the country. The Federal Highway Administration (FHWA) has designated WMA as a focus area [18] and FHWA's Every Day Counts Initiative has identified WMA for accelerated deployment [19]. The introduction of WMA in the U.S. and Canada happened about the same time: the first trials in U.S. and Canada were conducted in 2004 and 2005, respectively [17].

\subsection{Industry Response}

So far, industry response to WMA has been positive and growing worldwide. The United States has become industry leader in WMA technologies and deployment as currently there are over 30 WMA technologies on the country's market. According to NAPA [19], 106.4 million tons of WMA were produced in 2013 (almost a third of the asphalt tonnage), representing over 533\% increase in WMA production since 2009. In Australia, field trials started in 2010 with the view to developing specifications for WMA [20]. South Africa released its WMA Manual in 2011 after successful trials between 2008 and 2010. The trials included mixes with up to $40 \%$ reclaimed asphalt pavement material and recorded mixing and paving temperatures $25^{\circ} \mathrm{C}-30^{\circ} \mathrm{C}$ lower than those of HMA mixes [21]. According to Naidoo et al. [21], the progress towards WMA deployment in South Africa was driven by the need and passion for environmentally sustainable road building solutions. The growing acceptance of WMA is based on confirmation of its economic, environmental and performance benefits relative to conventional HMA, and it is anticipated that WMA will soon become the standard practice within the industry [13] [17] [22].

\subsection{Viscosity and Temperature Reduction Techniques}

A number of strategies have been developed to achieve reduced mix production temperatures. These include the use of organic additives, chemical additives and foaming techniques. Organic additives, which are described as "intelligent fillers", provide reduced viscosity at mixing temperatures and increased viscosity at service temperatures of WMAs [17]. At temperatures above the melting point of the organic additives, the viscosity of the binder is reduced to facilitate lower mix production temperatures, whereas at temperatures below the melting point of the additives, the stiffness of the binder is increased [23]. Hence, organic additives with melting points higher than the expected in-service pavement temperatures are selected to prevent permanent deformation [12]. Some proprietary organic additives are Asphaltan-B, Sasobit, and Shell Thiopave.

Chemical additives, on the other hand, do not reduce the viscosity of asphalt binder; rather they are surfactants added to the binder in a typical concentration of $0.30 \%$ by mass of the asphalt binder to improve the coating capability of the binder at lower mixing temperatures. This enables placement of the mix at temperatures about $20^{\circ} \mathrm{C}-30^{\circ} \mathrm{C}$ below that of conventional HMA [16] [17]. Examples include Evotherm, HyperTherm, and REVIX.

When foaming techniques are used in WMA production, controlled amounts of water are introduced to heated asphalt binder to cause a rapid expansion of the water, and accordingly the asphalt binder. This results in a temporary reduction in the viscosity of the binder which facilitates aggregate coating and improved workability at reduced temperatures. At pavement service temperature, the binder viscosity becomes normal. Methods of introducing water to the binder include the use of expansion chambers, wet sand and additives that trap crystallized water [17].

\section{Sustainability Benefits}

Reduction in asphalt concrete production and placement temperatures offered by WMA results in several environmental, economic and social performance and construction benefits in support of sustainable development. The sustainability benefits of WMAs derive from;

- Low energy use for production and placement, 
- Low emission of greenhouse gases,

- Conservation of natural resources,

- Increased reuse of old asphalt in new asphalt mixes.

These benefits notwithstanding, it is recognized that cost increase may arise from plant modification, cost of additives and technology licensing fees. However, such costs are likely to be offset by cost reductions due to lower production temperatures and less plant wear. Depending on the interaction of these factors, the costs of WMA production may be expected to be similar to or slightly higher than those of normal HMA [16]. As WMA technologies are further improved and their use becomes the standard practice, it is expected that the material will become more cost effective. Even now, favorable cost comparisons between HMA and WMA have been reported for WMA highway rehabilitation project in Canada which showed overall cost neutrality in terms of average project costs for similar HMA projects within the same region [24]. Some of the documented benefits of WMA are reviewed next.

\subsection{Environmental Benefits}

Reduction in greenhouse gas emissions is a significant benefit associated with WMA production. Studies show that greenhouse gas emissions during WMA production reduce in the same proportion as energy savings, estimated to range from 25\% to 50\% [16] [17]. Croteau and Tessier [17] have estimated that 20\% to 35\% energy savings in WMA production equates to $4.1 \mathrm{~kg}$ to $5.5 \mathrm{~kg}$ of $\mathrm{CO}_{2}$ equivalent per ton of WMA. Accordingly, 0.4 million tons less $\mathrm{CO}_{2}$ would be produced annually if the entire 63 million tons of asphalt produced in Germany were lower temperature asphalt, representing a potential reduction of about 25\% [13]. Alderson [22] concluded from a review of studies in Australia that lower plant emissions were associated with WMA, noting that the actual reduction depended on the condition of the plant, type of fuel, weather conditions during production, and the type of technology used. Keches and LeBlanc [25] estimated that cutting down HMA production temperatures by $20^{\circ} \mathrm{C}$ could reduce the combined $\mathrm{CO}_{2}$ emissions from both the fuel and asphalt used in the production by about 44\%. The data in Table 1 [26] show some effects of mix production temperature on greenhouse gas emissions.

D'Angelo et al. [12] reported the reductions in emissions associated with WMA in Table 2.

It is evident from Table 1 and Table 2 that WMA, produced at about $130^{\circ} \mathrm{C}$, generates less greenhouse gas emissions than HMA. In Canada, the Ministry of Transportation of Ontario measured greenhouse gas emissions on WMA projects, including carbon dioxide $\left(\mathrm{CO}_{2}\right)$, carbon monoxide $(\mathrm{CO})$, oxides of nitrogen $\left(\mathrm{NO}_{\mathrm{x}}\right)$, sulphur dioxide $\left(\mathrm{SO}_{2}\right)$, volatile organic compounds (VOC), and particulates and found relatively lower emissions [24], which corroborated other research findings. Given the millions of tons of asphalt mix produced worldwide, it is

Table 1. Emission changes due to mixing temperatures (kg/ton of asphalt mix production) [26].

\begin{tabular}{cccccc}
\hline Mixing temperature $\left({ }^{\circ} \mathbf{C}\right)$ & $\mathbf{C O}_{2}$ & $\mathbf{C H}_{\mathbf{4}}$ & $\mathbf{N}_{\mathbf{2}} \mathbf{O}$ & $\mathbf{C O}_{2}$ equivalent & Change relative to 155 ${ }^{\circ} \mathbf{C}(\%)$ \\
\hline 175 & 36.3 & 0.0018 & 7 & 36.6 & 4.6 \\
155 & 34.7 & 0.0018 & 7 & 35.0 & 0 \\
130 & 32.7 & 0.0018 & 7 & 33.0 & -5.7 \\
\hline
\end{tabular}

Source: Ripoll and Farré [26].

Table 2. Reduction (\%) in plant emissions during WMA production.

\begin{tabular}{|c|c|c|c|c|}
\hline \multirow{2}{*}{ Emission } & \multicolumn{4}{|c|}{ Country } \\
\hline & Norway & Italy & Netherlands & France \\
\hline $\mathrm{CO}_{2}$ & 31.5 & $30-40$ & $15-30$ & 23 \\
\hline $\mathrm{SO}_{2}$ & - & 35 & - & 18 \\
\hline VOC & - & 50 & - & 19 \\
\hline $\mathrm{CO}$ & 28.5 & $10-30$ & - & - \\
\hline $\mathrm{NO}_{\mathrm{x}}$ & 61.5 & 60.70 & - & $18\left(\right.$ as $\left.\mathrm{NO}_{2}\right)$ \\
\hline Dust & 54 & $25-55$ & - & - \\
\hline
\end{tabular}


evident that increased use of WMA can result in considerable reduction in greenhouse gas emissions.

Adding reclaimed asphalt pavement (RAP) to WMA mixtures has been found to further minimize greenhouse gas emissions. A Colas SA study found that $15 \%$ RAP for a surface course $(50 \mathrm{~mm})$ and $25 \%$ for a base course $(100 \mathrm{~mm})$ can potentially reduce the total energy requirement to one litre of diesel fuel per square metre of pavement compared to the same pavement structure constructed with conventional asphalt mixtures, representing $\mathrm{CO}_{2}$ equivalent emission reduction of $2.4 \mathrm{~kg} / \mathrm{m}^{2}$ [17]. Alderson [22] cites the data in Table 3, based on mix production temperature of $155^{\circ} \mathrm{C}$, to show the effect of increasing RAP content on greenhouse gas emissions.

It is important to mention that studies show that WMA facilitates the inclusion of high proportions of RAP compared with HMA. The use of RAP in itself has major sustainable benefits, hence adding it to WMA mixtures will yield even greater benefits. The National Asphalt Pavement Association estimates that adding 25\% RAP to WMA could potentially offset pavement lifecycle greenhouse gas emissions by $15 \%$ to $20 \%$, with potential total savings in greenhouse gas emissions of 3 million tons annually [8].

\subsection{Economic Benefits}

\subsubsection{Reduced Fuel Use}

WMA technologies are comparatively energy-efficient due to their ability to reduce mix production temperatures. This translates to reduced fuel costs and results in savings that may range from $11 \%$ to $35 \%$, which correspond to 1.5 - 2.0 liters of fuel per ton of WMA mix [12] [17]. Anderson and May [27] as cited by Nicholls and James [13] found that reduction in production temperature by $10^{\circ} \mathrm{C}$ results in energy savings of $3 \%$ to $4 \%$, which corresponds to about $0.25 \mathrm{~kg}$ fuel per ton of asphalt produced. NAPA [8] indicates that WMA reduces fuel consumption during production by an average of $20 \%$, which decreases total life-cycle greenhouse gas emissions by $5 \%$; the energy savings is equivalent to cutting one million tons of asphalt production annually.

It is argued by some that fuel savings from WMA production may not be substantial to immediately offset the cost of the initial investment [27] as cited by Nicholls and James [13]. However, other benefits of WMA, such as increased production or late season paving, provide additional economic incentives [13]. In addition, less fuel use demonstrates an important principle of sustainable development; minimization of material use. The economic gains of less energy use also have social benefits: 1 ) asphalt industry businesses gain more profit and continue to provide employment, and 2) project costs become competitive.

\subsubsection{Potential for Increased RAP in WMA}

Excessive binder aging due to high production temperatures is a major concern that does not ordinarily motivate high proportions of RAP in conventional HMA production. However, in the case of WMA production, it is believed that reduced production temperatures minimize binder aging which compensates for the aged RAP binder, thus allowing the use of high proportions of RAP [12]. Also, the improved workability enhances mixing and compaction of RAP-containing mixtures at lower temperatures [24]. According to NAPA [8], increasing RAP content to $25 \%$ of the average mix will reduce total lifecycle greenhouse gas emissions by $10 \%$ due to the elimination of fuel consumption required to acquire and process raw materials for virgin mix. This suggests that the ability to increase RAP content in mixes increases the potential for higher reductions in greenhouse gas emissions by the industry.

Field performance of mixes containing up to 50\% RAP has been generally positive [28]. Zaumanis and Mallick [29] reviewed the state-of-the-art approaches for increasing the amount of RAP in asphalt mixtures above $40 \%$ and concluded that RAP content can be significantly increased with the application of good RAP management practices, readily available modern production technologies and advanced knowledge of mix design. Case studies from Germany, Netherlands, and South Africa have reported up to 50\% RAP content in mixes [12] [21]. Trials have been conducted in Germany with 90\% to 100\% RAP using WMA systems such as Aspha-min zeo-

Table 3. Emission reduction when using RAP (kg/ton of asphalt concrete production).

\begin{tabular}{llllll} 
RAP (\%) & $\mathbf{C O}_{2}$ & $\mathbf{C H}_{\mathbf{4}}$ & $\mathbf{N}_{\mathbf{2}} \mathbf{O}$ & $\mathbf{C O}_{\mathbf{2}}$ equivalent & Reduction (\%) \\
0 & 34.7 & 0.0018 & 7 & 35.0 & 0 \\
10 & 32.5 & 0.0017 & 6 & 32.8 & 6.3 \\
20 & 30.4 & 0.0016 & 8 & 30.6 & 12.6 \\
\hline
\end{tabular}

Source: Ripoll and Farré, 2008 [26]. 
lite and Sasobit [12].

The economic benefits of increased RAP usage include savings in material cost arising from reducing the amount of virgin aggregates and binders in new mixtures, as well as reduced costs associated with transporting virgin materials to plant sites. Environmental benefits include reduced emissions and fuel usage associated with extraction and transportation of virgin materials, reduced demands on non-renewable resources, and reduced landfill space for disposal of construction debris [28]. As it were, pushing for mixes having 100\% RAP content could create a cycle of reuse that optimizes the utilization of natural resources and makes pavement construction a sustainable process [29]. What is more, the process of reclaiming and processing RAP materials has a very low environmental impact [8].

\subsubsection{Extension of Paving Season}

The improved workability of WMA at lower temperatures relative to HMA allows the placement and compaction of WMA at lower temperatures, thus extending the paving season in cold weather. According to case studies in Germany, paving was completed at ambient temperatures between $-3^{\circ} \mathrm{C}$ and $4^{\circ} \mathrm{C}$ [12]. Not only is the extended paving season economically beneficial to paving contractors, it also provides job security for asphalt industry workers.

\subsubsection{Longer Haulage Distances}

Increasing the mixing temperature of WMA to allow for long haul distance is possible without causing significant premature aging of the binder [17]. Consequently, WMA could be hauled over long distances while maintaining good workability for placement and compaction. Reportedly, WMA produced with Sasobit was hauled up to 9 hours in Australia, yet it was possible to place the mix at acceptable temperatures [12]. The ability of WMA to allow longer haulage distances and extended paving season is facilitated by the material's reduced rate of cooling due to the low temperature gradient between the mix and its ambient temperature, and also due to reduced binder viscosity at lower temperatures [12]. The longer haul distances eliminate the need for low efficiency mobile asphalt plants on projects in remote locations [24]. Siting asphalt plants in remote areas has social benefits and may speed up the permitting process, although it may be associated with high haulage costs. A full cost analysis can confirm the net benefit of such a decision.

\subsection{Social Benefits}

\subsubsection{Reduced Exposure}

Due to the relatively low production and placement temperatures, WMA provides comfortable working conditions, both at the asphalt plant and at the paving site as workers experience cooler working temperatures, reduction in the emission of fumes (see Figure 1) and odors.

Reduction in the emission of fumes and odor during placement of WMA has been found to range from $30 \%$ to $50 \%$ [12] [27] and from 30\% to $90 \%$ behind the paver [17]. According to EAPA [16], as a rule of thumb, the release of fumes is reduced by about half for each $10^{\circ} \mathrm{C}$ reduction in placement temperature.

The Ministry of Transportation of Ontario (Canada) found that dust was reduced by $30 \%$ behind the paver and
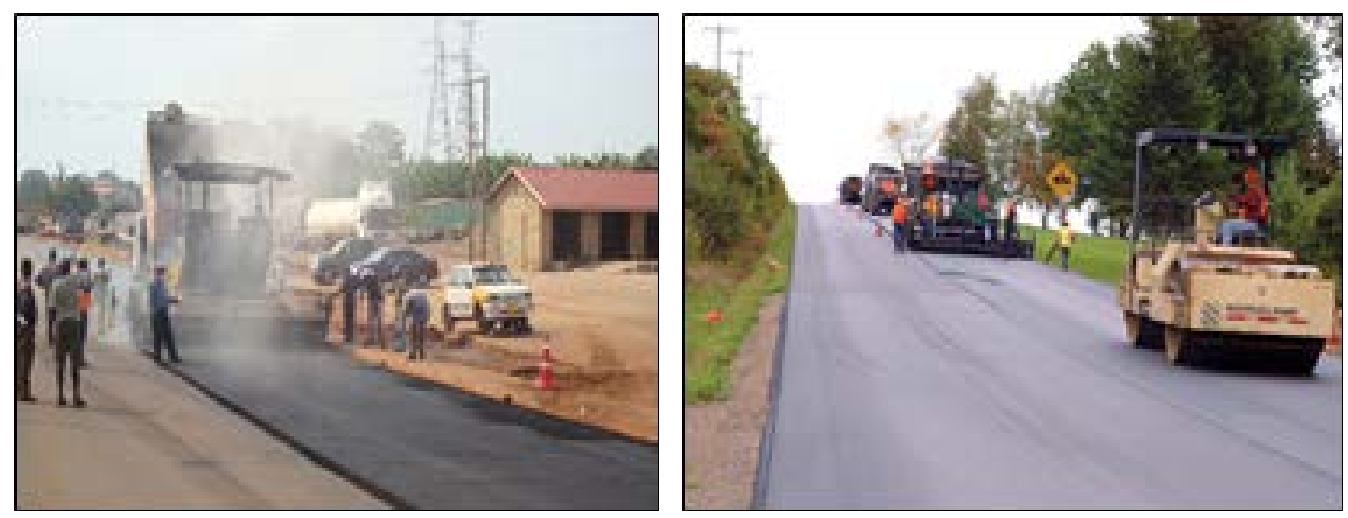

Figure 1. Fumes from HMA (left) and none from WMA (Right) [Photo: Croteau and Tessier [17]]. 
$85 \%$ at the location of the paver operator, benzene soluble fraction was reduced by $63 \%$ behind the paver and $72 \%$ at the location of the paver operator, and opacity values of HMA were nearly triple that of WMA at both locations [24]. Comfortable working conditions associated with WMA have been found to improve worker productivity and retention [12]. Although asphalt fumes are not known to be carcinogenic, volatile organic compounds (VOCs), such as polycyclic aromatic hydrocarbons (PAHs), which are emitted adversely impact health [13]. According to Olard et al. [30], a reduction of $13^{\circ} \mathrm{C}$ in the production temperature of asphalt mixtures reduces PAH emissions by $50 \%$.

\subsubsection{Reduced Fuel Use and Vehicular Emissions within Construction Zones}

WMA alleviates road user frustration, delay costs, increased fuel use, and vehicle emissions due to road closures during construction. The lower paving temperature of WMA means that the mat temperature at close of compaction is near its service temperature, thus allowing for early trafficking. For the same reason, multiple lifts can be placed sooner [17]. According to Nicholls et al. [13], reduction in placement temperature by $20^{\circ} \mathrm{C}$ allows opening to traffic between 20 and 40 minutes earlier. However, there are concerns that workability would not dissipate before trafficking, and this may cause rutting [31].

\subsection{Performance}

Studies [8] [16] [17] have shown that WMA performs equally or possibly better than HMA and that both materials have similar versatility. WMA has been 1) used in dense-graded, stone matrix, mastic, and open-graded friction-course mixes; 2) used with polymer-modified binders; 3 ) placed in pavements with traffic expected to exceed 30 million 18-kip-equivalent single-axle loads and in a range of layer thicknesses; and 4) paved at bus stops, on airfields, and on port facilities [12]. In all these applications, WMA exhibited similar or better performance, including improved compaction, similar stiffness and rutting resistance, improved resistance to fatigue and thermal cracking, similar or less moisture damage and greater durability compared with HMA [12]. A study of Sasobit WMA by Keches and LeBlanc [25] showed high tensile strength and relatively low change in strength after laboratory aging, suggesting the potential to maintain a high strength during in-service aging.

Controlled vehicle load and falling weight deflectometer tests conducted on site and in an accelerated pavement loading facility have shown similar performance of WMA and HMA mixtures [32] as cited by Nicholls and James [13]. Hurley et al. [33] determined volumetric properties, rutting susceptibility, moisture resistance, and dynamic modulus of field-produced WMA mixtures and found that the WMA mixtures performed equal to or better than the control HMA mixtures. Also, wheel track test conducted on WMA samples produced rut depths comparable to HMA samples [24]. Due to good compaction and joint quality, less binder aging, improved resistance to rutting and thermal cracking characteristics of warm-mix asphalt, the material has the potential to provide superior performance to minimize pavement life-cycle cost relative to HMA [24].

In a comprehensive review of WMA performance studies, Nicholls and James [13] concluded that 1) the deformation resistance of WMA depended on the technology used and it is generally acceptable and often better than HMA; 2) stiffness is marginally lower for WMA than HMA, but the difference may be insignificant with a suitable choice of material; 3) there appears to be a small decrease in fatigue resistance of WMA compared with HMA, although the actual situation will depend on the technology used; 4) suitable low air voids contents can be achieved with WMA; 5) the moisture susceptibility of WMA appears to be technology-dependent and could be corrected with anti-stripping agents. The implication of all these findings on sustainability is that WMA pavement life will lengthen. As a result, demand for virgin construction materials will reduce with its attendant benefits, and public funds may be available to cater for other social needs. As noted, a sustainable pavement promotes environmental stewardship, enhances economic benefits, and improves quality of life.

\subsection{Construction}

A review of literature suggests that the machinery used for the production, transportation, placement and compaction of HMA are the same as those needed for WMA, although minor modifications to the asphalt plant may be required depending on the WMA technology. As previously mentioned, WMAs can be hauled over long distances due to the possibility to produce them at an increased temperature without damaging the binder, as well as the reduced cooling rate due to the lower temperature gradient between the mix and the ambient temperature. Both WMA and HMA have similar paving and compaction operation characteristics. Volumetric properties are 
achievable with standard paving machinery and rolling patterns as prevail with HMA [34]. Some studies have found that equal or higher field densities may be obtained with WMA compared with equivalent HMA mixes [17]. The use of practically the same paving equipment in both HMA and WMA paving operations suggests that the paving crew need not undergo specialized training in order to successfully construct WMA pavements, thus saving man-hours.

Reported paving-related benefits of WMA include 1) ability to pave in cold weather and yet obtain desired densities; 2) ability to have good workability after long haulage; 3) reduced compaction effort; 4) ability to incorporate higher proportions of RAP; and 5) ability to place multiple lifts within a short time [9] [12] [16] [17]. It is believed that more uniform compaction is achieved with WMA because its compaction temperature allows the roller train to be better spaced so as to ensure proper mat coverage [27]. Politano [24]) reports that compaction results on WMA trials in Canada were equal or better than those of HMA, and resulted in some contractors receiving bonuses.

Good compaction is critical to well-performing pavements, so most agencies base project acceptance on it. It is becoming increasingly common for contractors to use WMA technologies as compaction aid in order to achieve uniform density with reduced compactive effort [9] [12]. Additionally, the lower placement temperature of WMA facilitates its use for deep patching, thus making it possible to place multiple lifts within a short time. During the rehabilitation of the Frankfurt Airport, trenches were paved with $288 \mathrm{~mm}$ of WMA in 7.5 hours and immediately opened to jet aircraft traffic at a temperature of $85^{\circ} \mathrm{C}$ without deformation [17] [24]. The construction benefits of WMA indicate that the construction process will deliver a competent pavement that will provide sustainable benefits such as less agency and road user costs, and exogenous benefits such as road user satisfaction.

\section{Limitations of WMA}

The review has shown that warm mix asphalt provides significant benefits that are consistent with the principles of sustainable development. An advantage associated with the high temperatures deployed in conventional hot-mix production is complete drying of aggregates and probable total elimination of any potential problems associated with moisture damage. In the case of WMA production, concerns exist about the possibility that the low production temperatures may not completely dry the aggregates, and consequently increase the potential for moisture damage. It is also believed that WMA produced with water-based technologies may lead to water entrapment within the asphalt concrete matrix which could, in the long term, trigger moisture susceptibility problems. So far, however, research on WMA moisture sensitivity does not show a common trend. The general caution, though, is that moisture damage may be influenced by the reduced production temperature and/or the type of additive used and, therefore, as it is done in the case of HMA, moisture-sensitivity testing and addition of anti-stripping agents may be necessary in the mix design process [17]. When this happens, mix production cost will increase. Also, some organic additives are thought to increase binder stiffness at lower temperatures, thus increasing the potential for thermal cracking. Some studies suggest that the stiffening effect is binder- and additive-specific, and that the reduced mixing temperature and the resulting reduced aging of the binder may well compensate for this stiffening effect [17].

The potential for increased RAP in WMA appears to provide a shot in the arm for sustainable practices in the paving industry but some industry experts hold the view that lack of guidelines for processing, handling, and characterizing RAP, as well as the inability of the Superpave mix design process to better handle high RAPcontent mixes are limitations to the use of higher RAP contents [28]. Finally, some maintain that evaluation of the sustainable benefits of WMA may have to consider the carbon footprint required in the production and transportation of WMA technologies. Transporting additives from distant locations, as opposed to local sources, may increase the $\mathrm{CO}_{2}$-emission and eventually change the effect from positive to negative [35].

\section{Conclusion}

The review has shown that warm mix asphalt provides significant benefits that are consistent with the principles of sustainable development. It is a promising approach to the production of asphalt mixtures at reduced temperatures. Research continues to provide convincing evidence of the considerable economic, environmental, performance and social benefits of warm mix asphalt. The remarkable response of the asphalt industry to WMA technologies since their inception nearly two decades ago strongly indicates that they are set to become the 
standard practice for the production of asphalt mixtures in the not-too-distant future, and coupled with other sustainable construction materials like reclaimed asphalt pavement, the sustainability of pavement construction can be further improved. Undoubtedly, further research into warm mix asphalt technologies and holistic examination of their potential benefits will help address current concerns that exist in the industry over warm mix asphalts.

\section{References}

[1] United States Department of Transportation (USDOT) (2006) 2006 Status of the Nation’s Highways, Bridges, and Transit: Conditions and Performance. Federal Highway Administration, Washington DC. http://www.fta.dot.gov/about/about_FTA_5208.html

[2] Federal Highway Administration (FHWA) (2009) Highway Statistics 2007. http://www.fhwa.dot.gov/policyinformation/statistics/2007

[3] World Commission on Environment and Development (WCED) (1987) Our Common Future: The Report of the World Commission on Environment and Development. World Commission on the Environment and Development, United Nations, New York. Oxford University Press for the Brundtland Commission, Oxford.

[4] Taylor (2008) as Cited in Sustainable Pavement Course Notes.

[5] Miller, T. and Bahia, H. (2009) Sustainable Asphalt Pavements: Technologies, Knowledge Gaps and Opportunities. Modified Asphalt Research Center, University of Wisconsin, Madison. https://uwmarc.wisc.edu/files/MARC-Sustainable-Asphalt-Pavements-white-paper.pdf

[6] Willis, J.R. (2014) Sustainable Pavement Course Notes. Auburn University, Auburn.

[7] Uzarowski, L. and Moore, G. (2008) Sustainable Pavements-Making the Case for Longer Design Lives for Flexible Pavements. Paper Presented at the Pavements: Quantifying Sustainability in Pavement Rehabilitation Projects Session of the 2008 Annual Conference of the Transportation Association of Canada, Toronto.

[8] National Asphalt Paving Association (NAPA) (2009) Black and Green: Sustainable Asphalt, Now and Tomorrow. Special Report Number 200. National Asphalt Paving Association, Lanham. http://www.hotmix.org/images/stories/sustainability_report_2009.pdf

[9] UN Press Release (2014) September 2014 Climate Summit Press Release. http://www.un.org/climatechange/summit/wp-content/uploads/sites/2/2014/05/Climate-Summit-main_FINAL-PR.pdf

[10] Brown, E.R., Kandhal, P.S., Roberts, F.L., Kim, Y.R., Lee, D.-Y. and Kennedy, T.W. (2009) Hot Mix Asphalt Materials, Mixture Design, and Construction. 3rd Edition. NAPA Research and Education Foundation, Lanham.

[11] Asphalt Institute (1983) Principles of Construction of Hot-Mix Asphalt Pavements. Manual Series No. 22, Lexington.

[12] D’Angelo, J., Harm, E., Bartoszek, J., Baumgardner, G., Corrigan, M., Cowsert, J., Harman, T., Jamshidi, M., Jones, W., Newcomb, D., Prowell, B., Sines, R. and Yeaton, B. (2008) Warm-Mix Asphalt: European Practice. International Technology Scanning Program, Federal Highway Administration. Report No. FHWA-PL-08-007. www.international.fhwa.dot.gov

[13] Nicholls, J.C. and James, D. (2013) Literature Review of Lower Temperature Asphalt Systems. Proceedings of the Institution of Civil Engineers—Construction Materials, 166, 276-285. http://dx.doi.org/10.1680/coma.11.00051

[14] Jones, W. (2004) Warm Mix Asphalt Pavements: Technology of the Future? Asphalt: The Magazine of the Asphalt Institute, 19, 8-11.

[15] Choi, Y. (2007) Warm Mix Asphalt (WMA) Review. Austraroads Technical Report. Austroads Publication No. APT91/07. www.austroads.com.au

[16] European Asphalt Pavement Association (EAPA) (2010) EAPA Position Paper on the Use of Warm Mix Asphalt. http://www.eapa.org/usr_img/position_paper/the_use_of_warm_mix_asphalt_january_2010.pdf

[17] Croteau, J.-M. and Tessier, B. (2008) Warm Mix Asphalt Paving Technologies: A Road Builder's Perspective. http://www.colascanada.ca/uploads/colascanada/File/expertise/WarmMixAsphaltPavingTechnologies.pdf

[18] Corrigan, M. (2006) Warm Mix Asphalt Technologies and Research. Federal Highway Administration, last updated 18 August 2006. http://www.fhwa.dot.gov/pavement/asphalt/wma.cfm

[19] National Asphalt Pavement Association (NAPA) (2013) Third Annual Asphalt Pavement Industry Survey on Recycled Materials and Warm-Mix Asphalt Usage: 2009-2012. Information Series 138. http://www.asphaltpavement.org/PDFs/IS138/IS138-2012_RAP-RAS-WMA_Survey_Final.pdf

[20] Australian Asphalt Pavement Association (AAPA) (2010) Warm Mix Asphalt Validation Project Brochure. http://www.h-a-d.hr/pubfile.php?id=356

[21] Naidoo, K., Lewis, T., Nortjè, W., Marais, H. and Rocher, K. (2011) Getting Started with Warm Mix Asphalt in South 
Africa. 2nd International Warm Mix Conference, Louis, 11-13 October 2011.

[22] Alderson, A. (2010) Review of the Environmental Aspects of Warm Mix Asphalt. Austroads Publication No. APT163/10. www.austroads.com.au

[23] Perkins, S.W. (2009) Synthesis of Warm-Mix Asphalt Paving Strategies for Use in Montana Highway Construction. Final Project Report. Western Transportation Institute, Montana State University, Bozeman.

[24] Politano, L. (2012) Warm Mix Asphalt-A Greener Alternative to Hot Mix Asphalt. A Paper Submitted for the Transportation Association of Canada 2012 Technical Excellence Awards (Environmental Achievement Awards). http://conf.tac-atc.ca/english/annualconference/tac2012/docs/session22/mto.pdf

[25] Keches, C. and LeBlanc, A. (2007) Reducing Greenhouse Gas Emissions from Asphalt Materials. BSc. Thesis, Worcester Polytechnic Institute, Worcester.

[26] Ripoll, J.O. and Farré, C.M. (2008) Evaluation of Greenhouse Gas Emissions from the Production of Hot Asphalt Mixtures. Proceedings of the 4th Eurasphalt \& Eurobitume Congress, Copenhagen, 21-23 May 2008.

[27] Anderson, R.M. and May, R. (2008) Engineering Properties, Emissions, and Field Performances of Warm Mix Asphalt Technologies. Interim Report Prepared for National Cooperative Highway Research Program NCHRP 9-47, Asphalt Institute, Lexington.

[28] West, R., Willis, J.R. and Marasteanu, M. (2013) Improved Mix Design, Evaluation, and Materials Management Practices for Hot Mix Asphalt with High Reclaimed Asphalt Pavement Content. National Cooperative Highway Research Program, Report Number NCHRP 752, Project No. 09-46.

[29] Zaumanis, M. and Mallick, R.B. (2014) Review of Very High-Content Reclaimed Asphalt Use in Plant-Produced Pavements: State of the Art. International Journal of Pavement Engineering, 16, 39-55. http://dx.doi.org/10.1080/10298436.2014.893331

[30] Olard, D., Le Noan, C. and Romier, A. (2007) Innovative Low Energy Asphalt Technique for Minimizing Impacts from Asphalt Plants to Road Works. Proceedings of 23rd PIARC World Road Congress Paris, Paris, 17-21 September 2007, World Road Association (PIARC).

[31] Hurley, G.C. and Prowell, B.D. (2006) Evaluation of Evotherm for Use in Warm Mix Asphalt. NCAT Report 06-02, National Center for Asphalt Technology, Auburn.

[32] Al-Rawashdeh, A.S. (2008) Performance Assessment of Warm Mix Asphalt (WMA) Pavements. MSc Thesis, Russ College of Engineering and Technology of Ohio University, Athens.

[33] Hurley, G.C., Prowell, B.D. and Kvasnak, A.N. (2009) Ohio Field Trial of Warm Mix Asphalt Technologies: Construction Summary. NCAT Report 09-04.

[34] Manolis, S., Decoo, T., Lum, P. and Greco, M. (2008) Cold Weather Paving Using Warm Mix Asphalt Technology. Proceedings of 2008 Annual Conference of the Transportation Association of Canada, Toronto, 21-24 September 2008, Polyscience Publications Inc., Laval.

[35] Nicholls, J.C. (2011) Shell Thiopave ${ }^{\mathrm{TM}}$ Sulphur Extended Asphalt Modifier. Proceedings of 5th International Conference Bituminous Mixtures and Pavements, University of Thessaloniki, Thessaloniki, 1-3 June 2011, 47.

World Commission on Environment and Development (WCED) (1987) Our Common Future: The Report of the World Commission on Environment and Development. World Commission on the Environment and Development. United Nations, New York. Oxford University Press for the Brundtland Commission. 